\title{
Theoretical Study on the Self, Water-Assisted and Au- to-assisted Dimer Proton Transfer Reaction in the N-Hydroxy-Methylen-Formamide
}

\author{
Rezika Larabi $^{1}$, Yamina Belmiloud ${ }^{1,2}$, Meziane Brahimi ${ }^{{ }^{*}}$ \\ ${ }^{1}$ Laboratoire de Physico-Chimie Théorique et de Chimie Informatique, Faculté de Chimie, University of Sciences and \\ Technology Houari Boumediene, Alger, Algérie. \\ ${ }^{2}$ Université M'Hamed Bouguerra, Rue de l'Indépendance, Boumerdes, Algérie. \\ E-mail: *mez_brahimi@yahoo.fr \\ Received May 11, 2011; revised June 17, 2011; accepted July 21, 2011
}

\begin{abstract}
The proton transfer in the isolated, mono and dehydrated forms, isolated dimers of N-Hydroxy Methylen Formamide (NHMF) have been completely investigated in the present study using Density Functional Theory (DFT), Möller-Plesset perturbation (MP2) and Hartree-Fock (HF) methods with the 6-31G ${ }^{*}$ and $6-311 \mathrm{G}^{*}$ basis sets. The barrier heights for both $\mathrm{H}_{2} \mathrm{O}$-assisted and auto-assistance reactions are significantly lower than that of the bare tautomerization reaction from NHMF to N-Formyl Formamide (NFF), implying the importance of the superior catalytic effect of $\mathrm{H}_{2} \mathrm{O}$ in the monomer of NHMF and important role of $\mathrm{HOCH}=\mathrm{N}-\mathrm{COH}$ for the intramolecular proton transfer.
\end{abstract}

Keywords: N-Hydroxy Methylen Formamide, Proton Transfer, HF, MP2 and DFT

\section{Introduction}

The importance of the amide functional group is demonstrated by the fact that the amide peptide bond is the basic linkage in peptides and proteins. The NHMF (Figure 1) [1] is the smallest $\mathrm{N}$-acyled Imidate which contains the two amide and oximin forms of the formamide tautomeric equilibrium.

The internal coordinates optimization of the different conformers: trans-trans, cis-cis and trans-cis lead to stables structures, respectively, of the same configuration that the initial input and no imaginary frequencies were found. The cis-trans optimization leads to a transition state. The cis-cis structure is stabilized by intra-molecular hydrogen bond between $\mathrm{H}_{8}$ and $\mathrm{O}_{4}$. The hydrogen bond generates in this conformer, on one hand the planarity of the system at all theoretical levels and an other hand an elongation of the double links $\mathrm{C}=\mathrm{N}$. The link $\mathrm{C}=$ $\mathrm{N}$ and $\mathrm{C}=\mathrm{O}$ are in the same plan. They do not constitute a delocalized system. The lengths of the links $\mathrm{C}=\mathrm{N}$ and $\mathrm{C}=$ $\mathrm{O}$, in the trans-cis conformer, correspond in all cases to the localized links by comparing them to the experimental data that we met for $\mathrm{C}=\mathrm{N}$ in the conjugated imines [2] and the $\mathrm{C}=\mathrm{O}$ in the formamide's family $[3,4]$. This is confirmed by the frequencies calculation which gives $v_{\mathrm{C}=\mathrm{N}}$ $=1671.82 \mathrm{~cm}^{-1}$ and $v_{\mathrm{C}=\mathrm{O}}=1718.75 \mathrm{~cm}^{-1}$ at MP2 $/ 6-31 \mathrm{G}^{*}$ level [1].

The conformational energy reaction cis-cis to trans-cis is endothermic of $4.29 \mathrm{kcal} / \mathrm{mol}$ at B3LYP/6-31G* level. The change of configuration passes by a transition state which is situated at an energy barrier of $26.20 \mathrm{kcal} / \mathrm{mol}$ at $\mathrm{HF} / 6-31 \mathrm{G}^{*}$ and $30.65 \mathrm{kcal} / \mathrm{mol}$ at $\mathrm{B} 3 \mathrm{LYP} / 6-31 \mathrm{G}^{*}$ level [1]. These energies correspond to a rotation around the double bond $\mathrm{C}_{1}=\mathrm{N}_{2}$ and are, respectively, two and three times larger than those we find in the literature for the rotation around the bond $\mathrm{C}_{2}-\mathrm{C}_{3}$ in the butadiene (13.23 $\mathrm{kcal} / \mathrm{mol}$ ) [5]. These activation energies are high enough to allow, in warm conditions, the passage from one to the other of the two conformers. Thus, the two structures ciscis and trans-cis exist; the first one in the absence of the other. The calculation of the electronic energy, corrected energy at the zero point and thermal energy, leads for HF, MP2 and B3LYP/6-31G ${ }^{*}$ to the same order of stability:

Cis-cis $>$ trans-cis $>$ trans-trans $>$ cis-trans.

In one hand the trans-cis form becomes strongly predominant in the polar solvent because of its high dipole moment, which is much greater than that of cis-cis forms. In fact, the dipole moment of the trans-cis structure of 
<smiles></smiles>

trans-cis

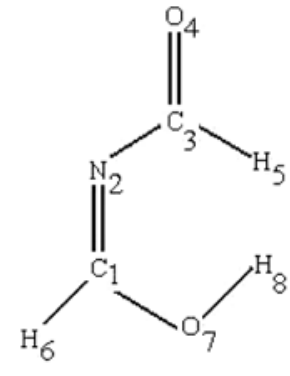

cis-trans<smiles></smiles>

cis-cis<smiles></smiles>

trans-trans

Figure 1. Different structures of the N-Hydroxy Methylen Formamide (NHMF) [1].

NHMF is 2.48, 2.52 (2.42) Debye in B3LYP and MP2 $\left(\mathrm{HF} / / 6-31 \mathrm{G}^{*}\right)$. In another hand, these two forms in the cis-cis tautomeric equilibrium are identical. All these facts explain our choice of the equilibrium tautomer study of the trans-cisforms of the NHMF molecule which contain in the same time the amide and imidic forms of the formamide molecules.

The formamide-formamidic tautomerization has been used to a model in large basic linkage in peptides and proteins. Several theoretical studies on the monohydrated (bi-hydrated) formamide-water complex have determined that the preferred mechanism for proton transfer to form formamidic acid proceeds via stable cyclic double or triple hydrogen bonded transition state [6-11].

The energy barrier for the formamide $\rightarrow$ formamidic acid isomerization was estimated by Wang et al. [8] to be $48.9 \mathrm{kcal} / \mathrm{mol}$ in the gas phase. But in the same article it was shown that a single $\mathrm{H}_{2} \mathrm{O}$ molecule directly assists the tautomerization of formamide lowers the barrier to 22.6 $\mathrm{kcal} / \mathrm{mol}$.

The present work has two purposes: 1) To perform the same studies with the NHMF molecules and to compare theses results; 2) To discuss the possibility that NHMF dimers may be involved in an effecting tautomerization.

\section{Computational Methods}

In this work, all computations were carried out by means of the Gaussian 03W [12]. All the geometries of local minima and transition state structures were optimized without symmetry restrictions (C1 symmetry was assumed) by the gradient procedure initially at the HF level and subsequently at the second order of closed shell Möller-Plesset perturbation theory [13].

The results have been compared with those obtained from the Functional Density Theory (DFT) by using the function of exact exchange of Becke (B3) [14] and the function of the gradient correction of Lee Yang Parr (LYP) [15]. The characteristics of local minima and transition states were verified by establishing that the matrices of the energy second derivatives (Hessians) have zero and one negative eigenvalues, respectively at all level of theory.

\section{Results and Discussion}

The structures and frequencies of the equilibrium geometry were discussed briefly in the introduction of this work and in detail by Brahimi et al. at the HF, post-HF (MP2) and density functional theory levels for the isolated NHMF [1].

\subsection{Self, Water-Assisted and Self-assisted Proton Transfer Reaction in the NHMF Molecules}

\subsubsection{Geometries}

Both formamide and formamidic forms to the tautomeric equilibrium of formamide molecules are present in the smallest N-acyled imidate NHMF (Figure 1) [1]. The self-proton transfer from $\mathrm{O}_{7}-\mathrm{H}_{8}$ to $\mathrm{N}_{2}$ in the NHMF gives the N-Formyl Formamide (NFF) molecules. Figure 2 shows the geometries of the reactants, transition states and products involved in the self, $\mathrm{H}_{2}$ Oassisted, $\left(\mathrm{H}_{2} \mathrm{O}\right)_{2}$ assisted and self-assisted NHMF proton transfer reactions obtained at HF, MP2 and DFT/B3LYP levels with 6-311G* basis.

For the self mechanism (NHMF TS NFF), the transition state appears to hold a co-planar four-memberedring. When we exam the structural changes from reactant to product, it can be seen that the $\mathrm{C}=\mathrm{N}-\mathrm{C}=\mathrm{O}$ dihedral angle fluctuate according to the theoretical level used, this angle worth $0.0(9.4)$ at the HF, 28.2(32.7) at the MP2 and 23.8(27.9) degrees at the B3LYP//6-31G ${ }^{*}$ (6$311 \mathrm{G}^{*}$ ), and the $\mathrm{C}=\mathrm{O}$ bond length does not vary from reactant to product via transition state. This proves once more that the $\mathrm{C}-\mathrm{N}$ bond length corresponds well to a simple bond and the $\mathrm{C}=\mathrm{N}$ and $\mathrm{C}=\mathrm{O}$ are not conjugated in 


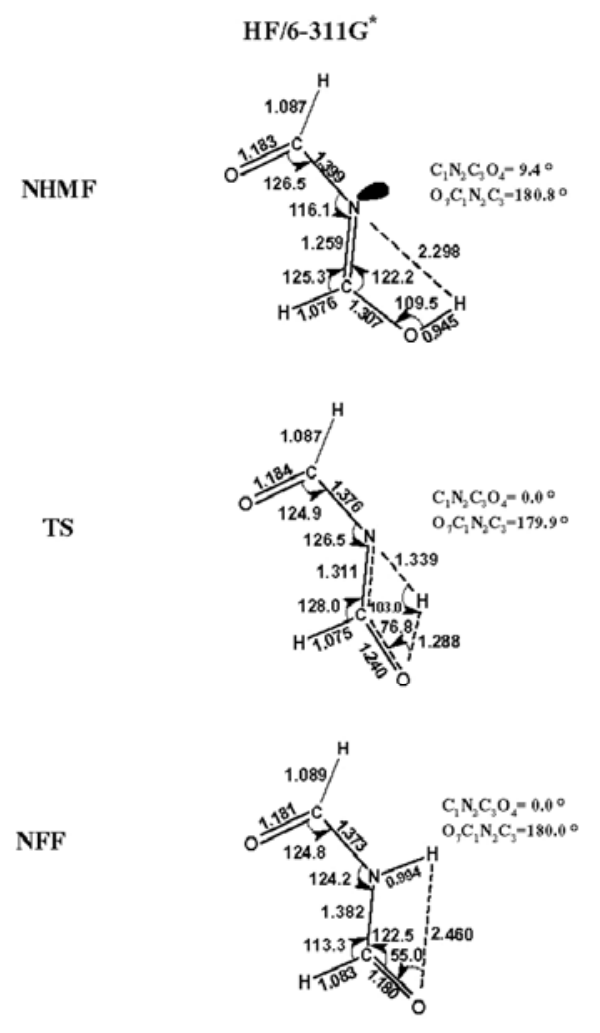

HF/6-311G"
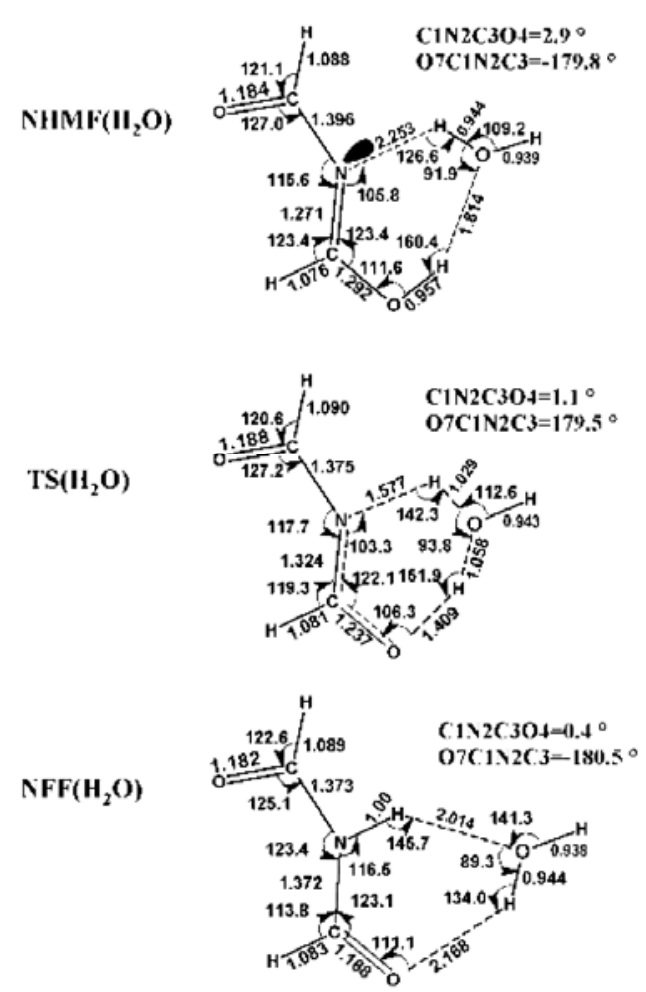
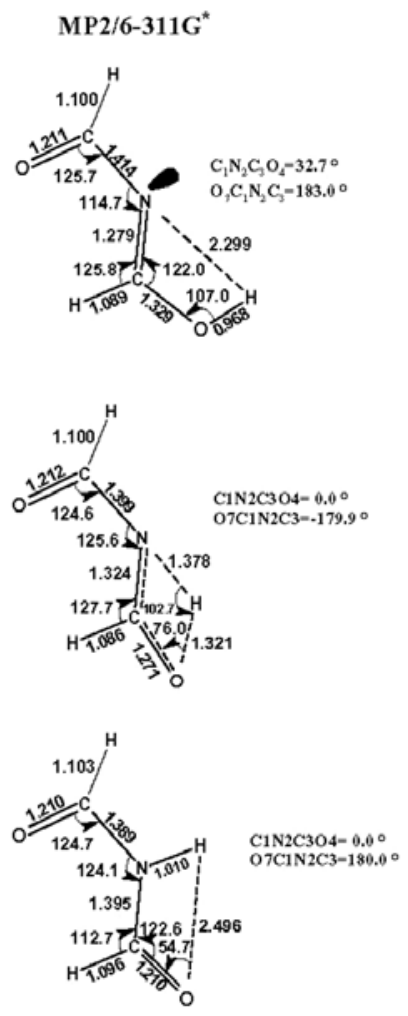

(a)

MP2/6-311G
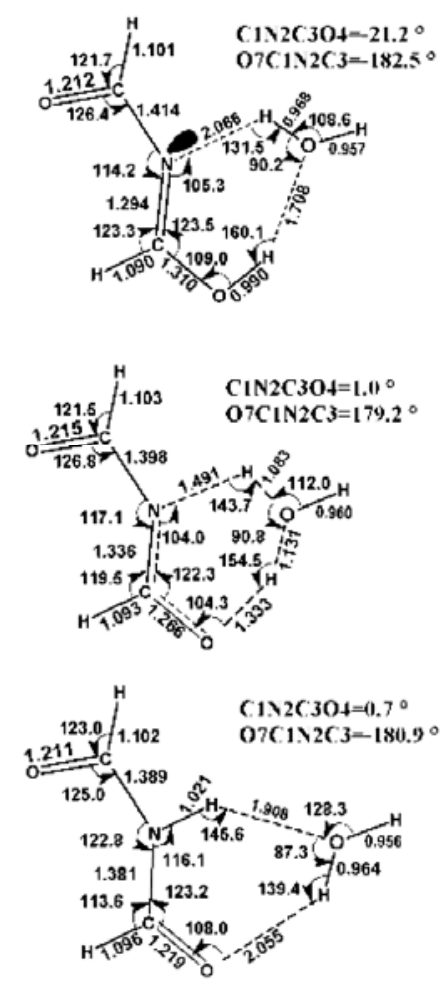

(b)
B3LYP/6-311G ${ }^{\text {* }}$
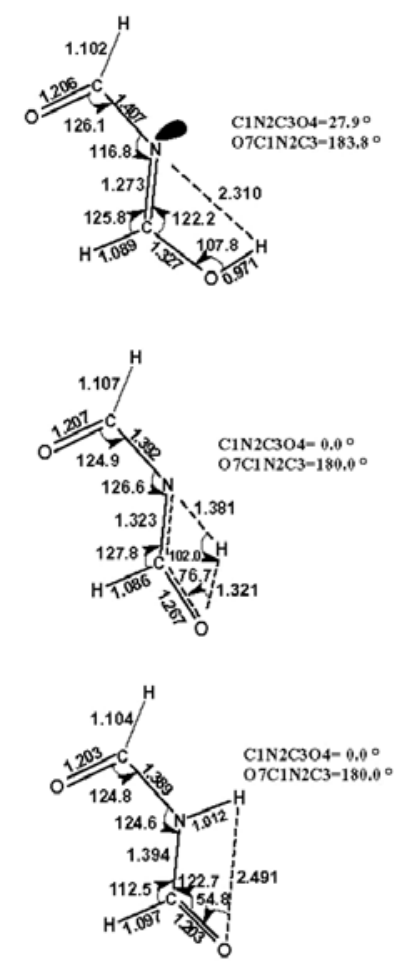

B3LYP/6-311C
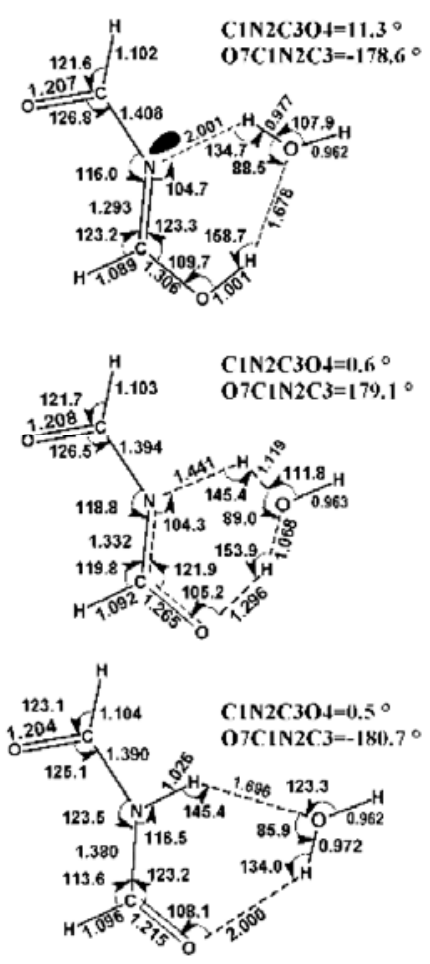
HF/6-311G
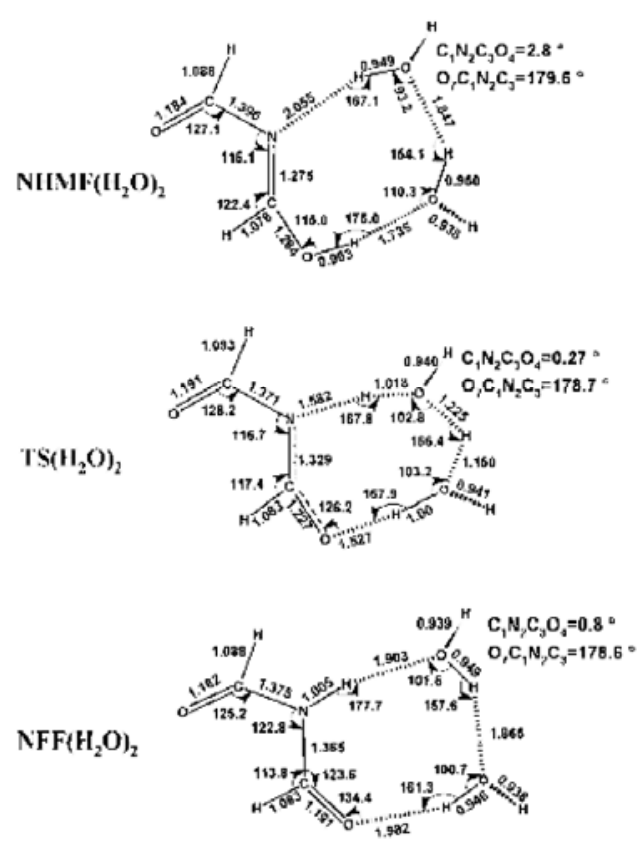

$\mathrm{HF} / 6-311 \mathrm{G}^{*}$

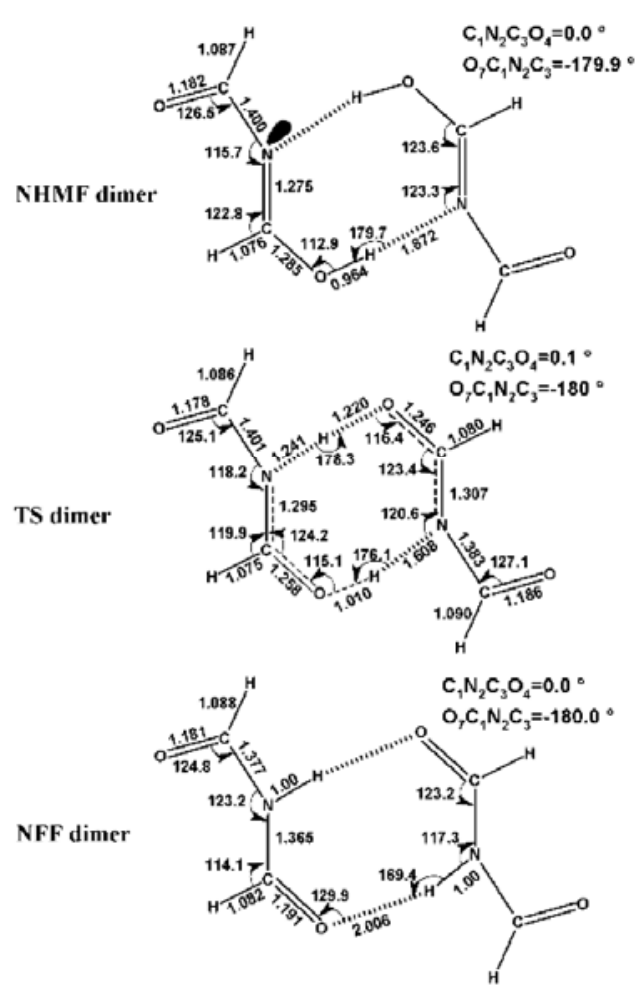

MP2/6-311G'
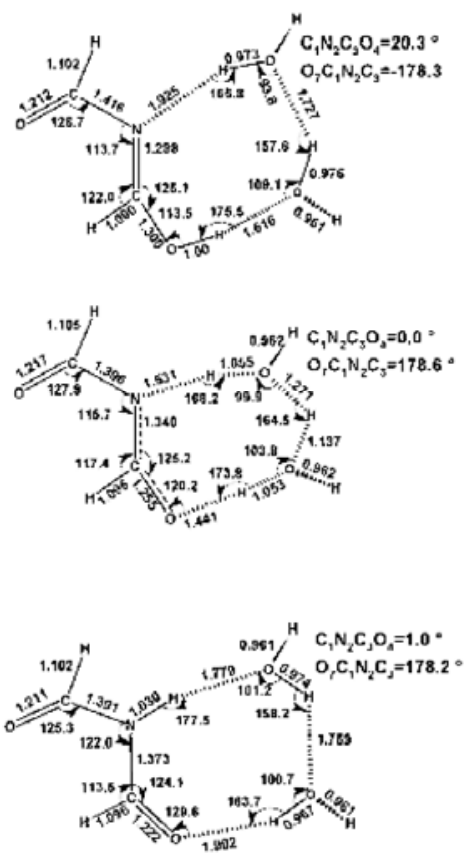

(c)

\section{MP2/6-311G}
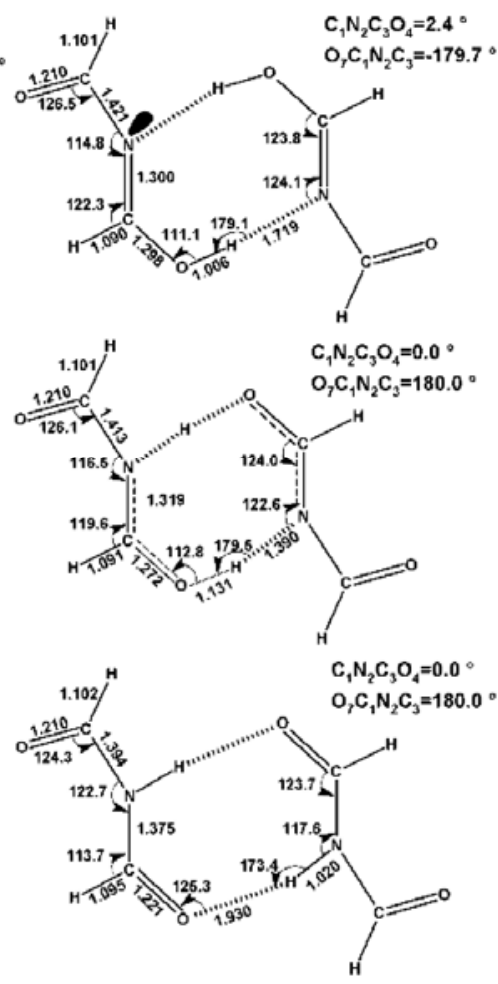

(d)

\section{B3LYP/6-311G'}
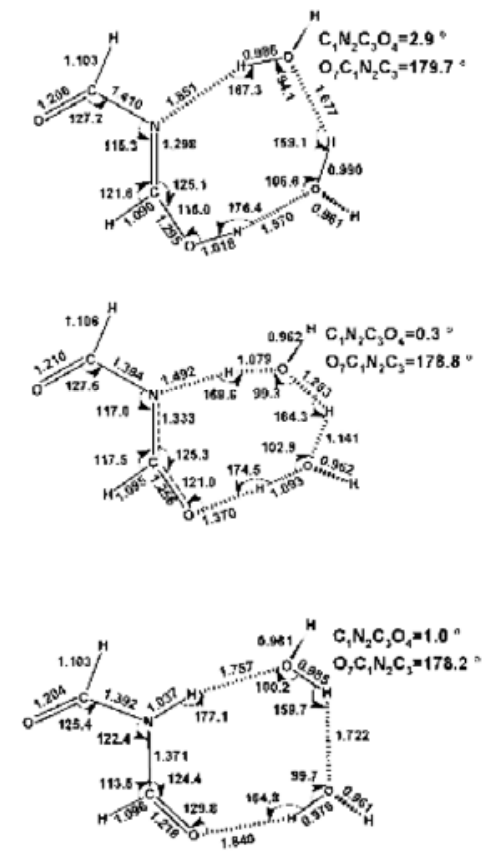

B3LYP/6-311G
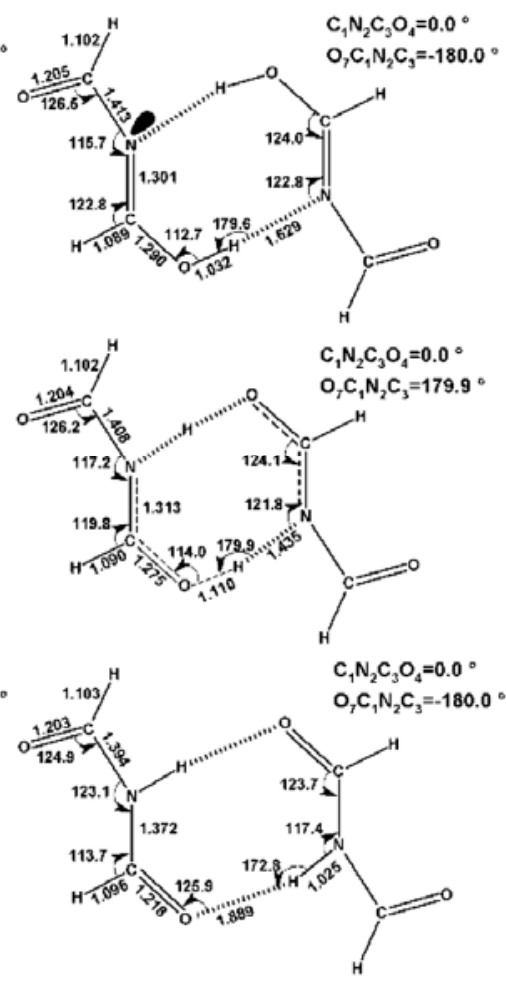

Figure 2. The optimized structures of the reactants, transition states and products of the (a) Self, (b) $\mathrm{H}_{2} \mathrm{O}$-assisted,(c) $\left(\mathrm{H}_{2} \mathrm{O}\right)_{2}$ assisted and (d) auto-assisted tautomeric process. The bond lengths are in $\AA$ and bond angles in degree. 
the NHMF molecules. Also we can see, the $\mathrm{N}_{2} \mathrm{C}_{1} \mathrm{O}_{7}$ bond angle is compressed by 13.7(13.3) degrees for the transition state at the MP2//6-31G $\left(6-311 \mathrm{G}^{*}\right)$ level. The $\mathrm{C}=\mathrm{N}$ bond to lengthen of 1.283(1.279) to 1.394(1.395) $\AA$ and the $\mathrm{C}-\mathrm{N}$ bond to contract of $1.413(1.414)$ to $1.388(1.389)$ $\AA$ to attain the NFF structure at the MP2//6-31G ${ }^{*}$ (6$311 \mathrm{G}^{*}$ ) level. In all cases, we remark that the $\mathrm{C}=\mathrm{O}$ bond narrowed when the $\mathrm{C}=\mathrm{N}$ to stretch out. The geometrical parameters, calculated with the DFT/B3LYP level, are in good agreement with those obtained with the MP2 level.

For $\mathrm{H}_{2} \mathrm{O}$-assisted tautomerization $\left(\operatorname{NHMF}\left(\mathrm{H}_{2} \mathrm{O}\right) \rightarrow\right.$ $\left.\mathrm{TS}\left(\mathrm{H}_{2} \mathrm{O}\right) \rightarrow \mathrm{FF}\left(\mathrm{H}_{2} \mathrm{O}\right)\right)$, the most stable geometry of reactant $\operatorname{NHMF}\left(\mathrm{H}_{2} \mathrm{O}\right)$ is the cyclic double-hydrogen bonded structure. The two hydrogen bonding distances are 2.205 (2.253) $\AA$ and 1.833 (1.814) $\AA$, respectively, at $\mathrm{HF} / / 6-31 \mathrm{G}^{*}$ $\left(6-311 \mathrm{G}^{*}\right)$ levels. These results are in good agreement with those obtained by Ai-Ping-Fu and Col. in the study of proton transfer in the formamide [11].

In the $\operatorname{NFF}\left(\mathrm{H}_{2} \mathrm{O}\right)$ product, it is also a double hydrogen bonded system with the two hydrogen bonds and are 2.044 (2.014) $\AA$ and 2.132 (2.168) $\AA$, respectively, at $\mathrm{HF} / 6-31 \mathrm{G}^{*}\left(6-311 \mathrm{G}^{*}\right)$ level. In comparison with the selftautomerization, the obvious difference is that the $\mathrm{N}_{2} \mathrm{ClO}_{7}$ angle has to be compressed by only 1.2 degrees at $\mathrm{MP} 2 / 6-311 \mathrm{G}^{*}$ level (for NHMF $\rightarrow \mathrm{NFF}$ is $13.3^{\circ}$ ). The passage of isolated NHMF tautomeric form to the hydrated ones leads a net variation of the $\mathrm{C}_{1} \mathrm{~N}_{2} \mathrm{C}_{3} \mathrm{O}_{4}$ dihedral angle. On DFT/B3LYP level, its value (23.8 without $\mathrm{H}_{2} \mathrm{O}$ ) becomes ( 4.7 with $\mathrm{H}_{2} \mathrm{O}$ ) degrees with $6-31 \mathrm{G}^{*}$ basis and (27.9) becomes 11.3 degrees with $6-311 \mathrm{G}^{*}$ basis. On MP2 level, its value passes from 28.2 to 12.6 degrees with $6-31 \mathrm{G}^{*}$ basis and from 32.7 to 21.2 degrees with 6 $311 \mathrm{G}^{*}$ basis. On HF level, its value passes from 0 to 2.8 degrees with $6-31 \mathrm{G}^{*}$ basis and from 9.4 to 2.9 degrees with $6-311 \mathrm{G}^{*}$ basis. Thus, the introduction of one water molecule has an effect on the planarity of the system but not the delocalization for the $\pi$ electrons. In fact, the $\mathrm{C}_{1}=\mathrm{N}_{2}$ and $\mathrm{C}_{3}=\mathrm{O}_{4}$ bonds correspond, in all cases, to a localized bonds. In the NFF structure, the solvent effect is practically vanished.

Similar to the $\mathrm{H}_{2} \mathrm{O}$-monomer assisted process, the $\left(\mathrm{H}_{2} \mathrm{O}\right)_{2}$-catalyzed mechanism, the reactions also started by the formation of the NHMF $\left(\mathrm{H}_{2} \mathrm{O}\right)_{2}$ which involves a co-planar eight membered-ring due to the formation of the hydrogen bonds. In the reaction process, two $\mathrm{H}_{2} \mathrm{O}$ molecules involve in assisting the passage of the proton from NHMF to NFF. As discussed above, from Figure 2 we can see the framework of NHMF monomer change greatly in TS than that TS $\left(\mathrm{H}_{2} \mathrm{O}\right)$ and TS $\left(\mathrm{H}_{2} \mathrm{O}\right)_{2}$. In addition, $\angle \mathrm{NHO}$ is $102.7^{\circ}$ at $\mathrm{MP} 2 / / 6-311 \mathrm{G}^{*}$ in TS, while $\angle \mathrm{NHO}$ and $\angle \mathrm{OHO}$ are $143.7^{\circ}$ and $154.5^{\circ}$ respectively at MP2 $/ / 6-311 \mathrm{G}^{*}$ in $\mathrm{TS}(\mathrm{H} 2 \mathrm{O})$, whereas $\angle \mathrm{NHO}, \angle \mathrm{OHO}$ et $\mathrm{OHO}$ are all closed to $180^{\circ}$ in $\mathrm{TS}\left(\mathrm{H}_{2} \mathrm{O}\right)_{2}\left(168.2^{\circ}\right.$, $164.5^{\circ}$ and $173.8^{\circ}$ at $\left.M P 2 / 6-311 G^{*}\right)$. This quasi-linear structure causes the proton easier to transfer in proceeding of $\operatorname{NHMF}\left(\mathrm{H}_{2} \mathrm{O}\right)_{2} \rightarrow \mathrm{TS}\left(\mathrm{H}_{2} \mathrm{O}\right)_{2} \rightarrow \mathrm{NFF}\left(\mathrm{H}_{2} \mathrm{O}\right)_{2}$ than in proceeding of $\operatorname{NHMF}\left(\mathrm{H}_{2} \mathrm{O}\right) \rightarrow \mathrm{TS}\left(\mathrm{H}_{2} \mathrm{O}\right) \rightarrow \mathrm{NFF}\left(\mathrm{H}_{2} \mathrm{O}\right)$ and $\mathrm{NHMF} \rightarrow \mathrm{TS} \rightarrow \mathrm{NFF}$. So the intimate involvement of water can assist the proton transfer. The two $\mathrm{H}_{2} \mathrm{O}$ molecules make easy the proton transfer from $\mathrm{O}_{7}$ towards $\mathrm{N}_{2}$.

For the NHMF self-assisted mechanism, the optimized geometries of the stationary points, transition state at HF, MP2 and DFT/B3LYP levels with $6-311 \mathrm{G}^{*}$ are also illustrated in Figure 2 being similar to the water-catalyzed reactions, the reactant of the NHMF dimer also forms a co-planar eight membered-ring via two equivalent hydrogen bonding. The hydrogen bond distance is 1.872 and $1.629 \AA$, respectively at $\mathrm{HF}$ and $\mathrm{B} 3 \mathrm{LYP} / / 6-311 \mathrm{G}^{*}$ level. Similarly, NFF dimmer also appears to be a cyclic double hydrogen bonded structure with the hydrogen bond distance is 2.006 and $1.889 \AA$, respectively at HF and $\mathrm{B} 3 \mathrm{LYP} / / 6-311 \mathrm{G}^{*}$ level. In NHMFdimer, the NHO angle is quasi-linear (179.9 at $\mathrm{B} 3 \mathrm{LYP} / / 6-311 \mathrm{G}^{*}$ level) causing the proton easier to transfer from the oxygen atoms towards the nitrogen ones. In all cases, the two forms NHMF-dimmer and NFF-dimer exhibit a plan structures.

\subsubsection{Energetic}

Figure 3 shows the energetic diagrams of the reactants, transition states and products involved in the 1) self, 2) $\mathrm{H}_{2} \mathrm{O}$-assisted, 3) $\left(\mathrm{H}_{2} \mathrm{O}\right)_{2}$-assisted and 4) self assisted NHMF proton transfer reactions obtained at HF, MP2 and DFT/B3LYP levels with 6-311G ${ }^{*}$ basis.

It appears that the NHMF $\rightarrow$ NFF energy reaction, with ZPE correction, is exothermic of $17.35,17.61$ and 17.17 $\mathrm{kcal} / \mathrm{mol}$. at the HF, MP2 and DFT/B3LYP//6-311G ${ }^{*}$ level, respectively, thus the NFF form is the most stable than that NHMF one.

The NHMF $\rightarrow$ NFF reaction passes through out a transition state situated at an energy barrier of 44.26, 44.32 and of $\mathrm{f} 19.16 \mathrm{Kcal} / \mathrm{mol}$. at the HF, MP2 and B3LYP//6-311G level, respectively. We think that the great barrier energy at the gas phases involve the simultaneous existence of the two NHMF and NFF molecules.

In one hand, Figure 3 shows that the NHMF $\left(\mathrm{H}_{2} \mathrm{O}\right) \rightarrow$ $\operatorname{NFF}\left(\mathrm{H}_{2} \mathrm{O}\right)$ is also exothermic. We note that the two NHMF and NFF hydrated molecules are slightly stabilized comparing to the isolated molecules. The energetic gap from the two reactions, hydrated and isolated, is reduced by $1.32(1.47), 1.12(1.27)$ and $3.25(3.23) \mathrm{kcal} / \mathrm{mol}$. at the HF, MP2 and DFT/B3LYP//6-31G ${ }^{*}\left(6-311 \mathrm{G}^{*}\right)$ level, respectively. We note also that the solvent effect decrease the barrier of the activation energy. The gap energy is 23.13(24.30), 22.37(23.83) and 8.80(10.15) $\mathrm{kcal} / \mathrm{mol}$. at the HF, MP2 and DFT/B3LYP//6-31G $\left(6-311 \mathrm{G}^{*}\right)$ level, 


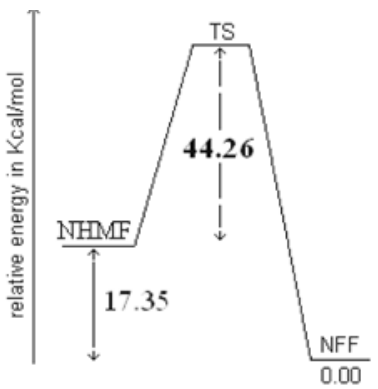

$\mathrm{HF} / 6 \cdot 311 \mathrm{G}^{*}$

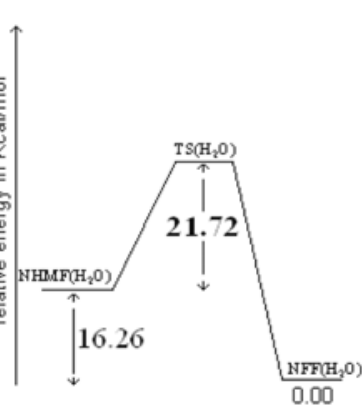

$\mathrm{HF} / 6-311 \mathrm{G}^{*}$

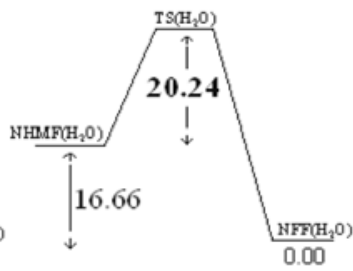

(b)

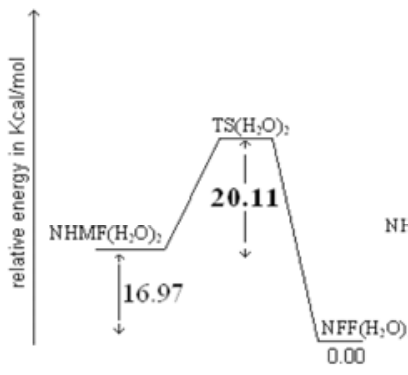

HF/6-311G*

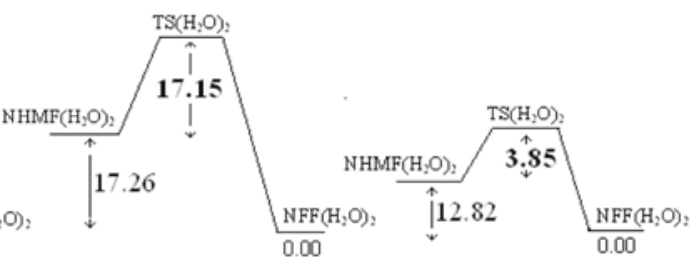

MP2/6-311G

B3LYP/6-311G*

(c)

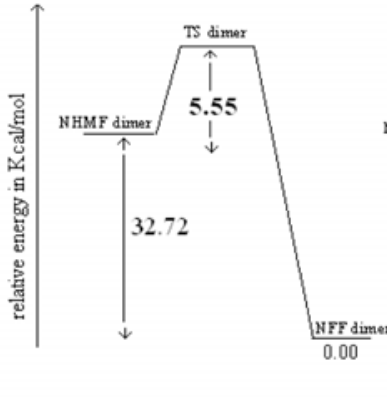

HF/6-311G*
MP2/6-311G
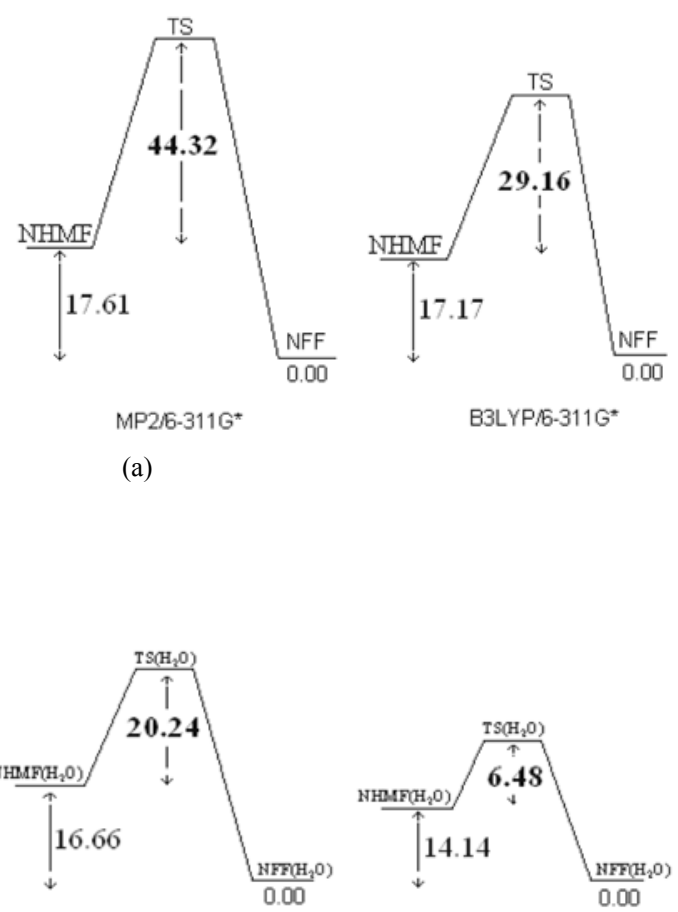

B3LYP/6-311G*

(a)

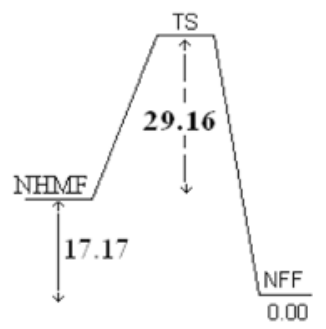

B3LYP/6-311G* 
respectively and the $6-31 \mathrm{G}^{*}$ to $6-311 \mathrm{G}^{*}$ basis extension increase slightly the activation barrier energy.

In another hand, the results, obtained at the different level of theory (with ZPE correction), show that the $\operatorname{NHMF}\left(\mathrm{H}_{2} \mathrm{O}\right)_{2} \rightarrow \mathrm{NFF}\left(\mathrm{H}_{2} \mathrm{O}\right)_{2}$ is exothermic by $16.97,17.26$ and $12.82 \mathrm{kcal} / \mathrm{mol}$ at the HF, MP2 and B3LYP//6-311G* level, respectively. These energies barriers are the same with those obtained for the NHMF $\left(\mathrm{H}_{2} \mathrm{O}\right) \rightarrow \mathrm{NFF}\left(\mathrm{H}_{2} \mathrm{O}\right)$ reaction for the proton transfer when we use one water molecule. The DFT/B3LYP level, conduce to the smallest energy barrier, see $3.85 \mathrm{kcal} / \mathrm{mol}$. This proves that the second water molecule addition doesn't have an effect on all the different energetic value.

The NHMF-dimer $\rightarrow$ NFF-dimer reaction is exothermic of $32.72,32.46$ and $26.56 \mathrm{kcal} / \mathrm{mol}$. at the HF, MP2 and DFT/B3LYP//6-311G ${ }^{*}$ level, respectively. The transition state, compared to the reactant one, is located at 5.55, $4.29 \mathrm{kcal} / \mathrm{mol}$. at the $\mathrm{HF}, \mathrm{MP} 2 / / 6-311 \mathrm{G}^{*}$, respectively and $-2.56 \mathrm{kcal} / \mathrm{mol}$. at the DFT/B3LYP//6-311G ${ }^{*}$ level. The latter value is probably due to a spontaneous NHMF NFF reaction. In the NHMF-dimer tautomerization, the energy barrier decreases about $90 \%$ in comparison with the self-NHMF tautomerization. According to this study, we conclude that the NHMF $\rightarrow \mathrm{NFF}$ reaction is auto-assisted by the NHMF-dimer proton transfer with the smallest barrier and a good structural arrangement that favoured the proton transfer mechanism.

\section{Conclusions}

The introduction of one or more water molecules has not a great effect of the NFF geometrical parameters contrary to the NHMF ones. The water molecule restores the planarity of the systems without affecting the no-conjugaison of the two $\mathrm{C}=\mathrm{N}$ and $\mathrm{C}=\mathrm{O}$ double bonds.

In all cases, the NFF molecules are more stable then the NHMF ones.

All theoretical levels, in aqueous environments, tend to decrease the energy barrier and the energy tautomerization compared to the gas phases. The HF and MP2 results promote the existence of the two NHMF and NFF separate molecules in the gas phase and hydrated ones. DFT leads a lower barrier energy compared with those obtained at the HF and MP2 levels.

Thus this method provides the simultaneous existence of the both molecules in the both environments. Finally, the NHMF $\rightarrow$ NFF reaction is established on a self-assisted NHMF dimmer with low barrier energies.

\section{References}

[1] M. Brahimi, Y. Belmiloud and D. Kheffache, "Hartree-Fock, Post Hartree-Fock and Density Functional
Theory Studies on Structure and Conformationa," Journal of Molecular Structure: THEOCHEM, Vol. 759, No. 1-3, 2006, pp. 1-10. doi:10.1016/j.theochem.2005.10.017

[2] S. Petai, "The Chemistry of the Carbone-Nitrigene Double Bond," Interscience Publishers, London, New York, 1970, Chapter 1, p. 2.

[3] P. Bour, C. N. Tam, J. Sopkova and F. R. Trouw, "Measurement and $\mathrm{Ab}$ Initio Modeling of the Inelastic Neutron Scattering of Solid N-Methylformamide," Journal of Chemical Physics, Vol. 108, No. 1, 1998, p. 351-359. doi:10.1063/1.475382

[4] V. R. Palakrishnan, G. Madrid, G. Cuevas and A. Thagler, "Density Functional Studies of Molecular Structures of N-Methyl Formamide, N,N-Dimethyl Formamide, and N,N-Dimethyl Acetamide," Proceedings of the Indian National Science Academy: Chemical Science, Vol. 112, 2000 , pp. 35.

[5] G. De Mare, Journal of Molecular Structure, Vol. 107, 1984, pp. 127-132.

[6] M. Nagaoka, Y. Okuno and T. Yamabe, "Chemical Reaction Molecular Dynamics Simulation and the Energy-Transfer Mechanism in the Proton-Transfer Reaction of Formamidine in Aqueous Solution," Journal of the American Chemical Society, Vol. 113, 1991, pp. 769.

[7] A. Engdahl, B. Nelander and P. O. Astrand, "Complex Formation between Water and Formamide," Journal of Chemical Physics, Vol. 99, No. 7, 1993, pp. 4894-4908. doi:10.1063/1.466039

[8] X. C. Wang, J. Nichols, M. Feyereisen, et al., "Ab Initio Quantum Chemistry Study of Formamide-Formamidic Acid Tautomerization," Journal of Physical Chemistry, Vol. 95, No. 25, 1991, p. 10419-10424. doi:10.1021/j100178a032

[9] J. D. Pranata and D. Geraldine, "Computational Investigations of Reactive Intermediates in the Acid-Catalyzed Proton Exchange in Formamide," Journal of Physical Chemistry, Vol. 99, No. 39, 1995, p. 14340-14346. doi:10.1021/j100039a022

[10] R. L. Bell, D. L. Taveras, T. N. truong and J. simons, “A Direct Ab Initio Dynamics Study of the Water-Assisted Tautomerization of Formamide," International Journal of Quantum Chemistry, Vol. 63, No. 4, 1997, pp. 861-874.

[11] A.-P. Fu, H.-L. Li, D.-M. Du and Z.-Y. Zhou, "Theoretical Study on the Reaction Mechanism of Proton Transfer In Formamide," Chemical Physics Letters, Vol. 382, No. 3-4, 2003, pp. 332-337. doi:10.1016/j.cplett.2003.10.070

[12] Gaussian 03, Revision A.1, M. J. Frisch, G. W. Trucks, H. B. Schlegel, G. E. Scuseria, M. A. Robb, J. R. Cheeseman, J. A. Montgomery, Jr., T. Vreven, K. N. Kudin, J. C. Burant, J. M. Millam, S. S. Iyengar, J. Tomasi, V. Barone, B. Mennucci, M. Cossi, G. Scalmani, N. Rega, G. A. Petersson, H. Nakatsuji, M. Hada, M. Ehara, K. Toyota, R. Fukuda, J. Hasegawa, M. Ishida, T. Nakajima, Y. Honda, O. Kitao, H. Nakai, M. Klene, X. Li, J. E. Knox, H. P. Hratchian, J. B. Cross, C. Adamo, J. Jaramillo, R. Gomperts, R. E. Stratmann, O. Yazyev, A. J. Austin, R. Cammi, C. Pomelli, J. W. Ochterski, P. Y. Ayala, K. Morokuma, G. A. Voth, P. Salvador, J. J. Dannenberg, V. G. 
Zakrzewski, S. Dapprich, A. D. Daniels, M. C. Strain, O. Farkas, D. K. Malick, A. D. Rabuck, K. Raghavachari, J. B. Foresman, J. V. Ortiz, Q. Cui, A. G. Baboul, S. Clifford, J. Cioslowski, B. B. Stefanov, G. Liu, A. Liashenko, P. Piskorz, I. Komaromi, R. L. Martin, D. J. Fox, T. Keith, M. A. Al-Laham, C. Y. Peng, A. Nanayakkara, M.Challacombe, P. M. W. Gill, B. Johnson, W. Chen, M. W. Wong, C. Gonzalez and J. A. Pople, Gaussian, Inc., Pittsburgh PA, 2003.

[13] C. Möller and M. S. Plesset, "Note on an Approximation
Treatment for Many-Electron Systems," Physical Reviews, Vol. 46, No. 7, 1934, p. 618-622. doi:10.1103/PhysRev.46.618

[14] A. D. Becke, "Density-Functional Exchange-Energy Approximation with Correct Asymptotic-Behavior," Physical Reviews A, Vol. 38, No. 6, 1998, pp. 3098-3100.

[15] C. Lee, W. Yang and R. G. Parr, "Development of the Colle-Salvetti Correlation-Energy Formula into a Functional of the Electron Density," Physical Reviews B, Vol. 37, No. 2, 1988, pp. 785-789. 